
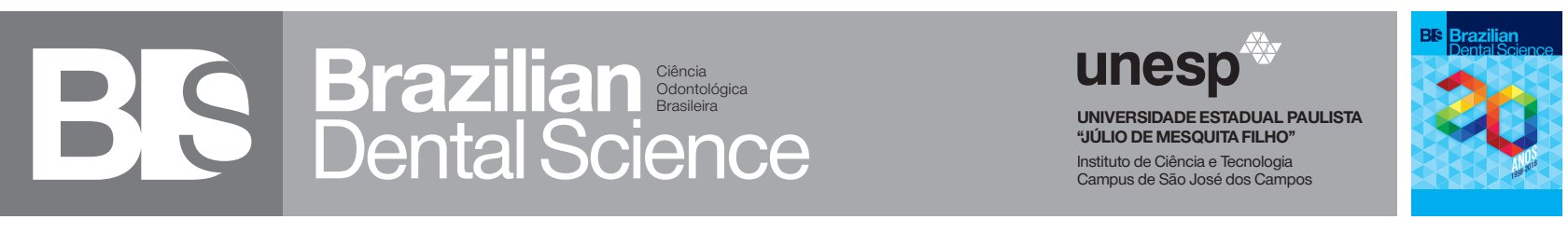

\title{
Effect of several repair techniques on the bond strength between composite resin and degraded Y-TZP ceramic
}

\author{
Efeito de várias técnicas de reparo na resistência de união entre resina composta e zircônia degradada \\ Vinícius Felipe WANDSCHER ${ }^{1}$, Luana BRONDANI ${ }^{2}$, Gabriel Kalil Rocha PEREIRA ${ }^{3}$, Renata Marques de MELO 4 \\ 1 - Franciscan University (UFN) (Prosthodontics Unit) - Santa Maria - RS - Brazil. \\ 2 - Private Practice. \\ 3 - Meridional Faculty - IMED - Passo Fundo - RS - Brazil. \\ 4 - São Paulo State University (Unesp) - Institute of Science and Technology, São José dos Campos - Department of Restorative Dentistry \\ - São José dos Campos - SP - Brasil.
}

\section{ABSTRACT}

Objective: To evaluate the bond strength of different repair treatments for composite resin to aged Y-TZP ceramics. Material and Methods: Zirconia blocks were cut into smaller specimens, sintered according to manufacturer's recommendations (final dimensions of $4 \times 4 \times 3 \mathrm{~mm}$ ), and randomly allocated into nine groups $(n=15)$ according to the surface treatment and presence/ absence of aging of the substrate (subjected to lowtemperature degradation - LTD), as follows: without LTD (Control: without treatment; TBS: tribochemical silica coating + silane + adhesive); with LTD (Control-LTD: without treatment; TBS-LTD: TBS with hydrothermal degradation; MoS-LTD: Monobond S + adhesive; MoPLTD: Monobond Plus + adhesive; MZP-LTD: Metal/ Zirconia Primer + adhesive; USB-LTD: Single Bond Universal; AP-LTD: Alloy primer + adhesive). LTD was simulated in an autoclave $\left(134{ }^{\circ} \mathrm{C}, 2 \mathrm{bar}, 5 \mathrm{~h}\right)$. The ceramic blocks were embedded in PVC cylinders with a self-curing acrylic resin; each surface treatment protocol was performed; a composite resin cylinder $(\varnothing: 3.25 \mathrm{~mm}$ and height: $3 \mathrm{~mm}$ ) was then build-up using split metallic matrices. All the specimens were aged (thermocycling + storage in water for 90 days) and subjected to the shear bond strength test using a universal testing machine ( $1 \mathrm{~mm} / \mathrm{min})$. The failure mode was classified into four types: adhesive, composite resin cohesive fracture, ceramic cohesive fracture, and mixed. The bond strength values were subjected to Mann-Whitney test. Results: Only air-abraded samples (TBS and TBS-LTD) survived thermocycling. More than $80 \%$ of the samples of the other groups presented pre-test failures. TBS groups presented higher values of bond strength (3.94) compared to TBSLTD (0.96). The predominant type of failure for the surviving samples were adhesive. Conclusion: Air particle abrasion is mandatory to improve the bond strength of the Y-TZP substrate; an aged substrate presents an even more unfavorable scenario for adhesion.

\section{KEYWORDS}

Dental prosthesis repair; Hydrothermal degradation; Zirconia; Shear bond strength; Sandblasting.

\section{RESUMO}

Objetivo: Avaliar a resistência de união ao cisalhamento gerada por diferentes técnicas de reparo em resina composta aderida em zircônia envelhecida (sujeita a degradação a baixa temperatura - LTD). Material e Métodos: blocos de zircônia foram seccionados em espécimes, sinterizados de acordo com o fabricante (dimensões finais de $4 \times 4 \times 3 \mathrm{~mm}$ ), e aleatorizados em nove grupos $(n=15)$ de acordo com o tratamento de superfície e presença/ausência de envelhecimento do substrato (LTD), conforme: sem LTD (Control: sem tratamento; TBS: tribosilicatização + silano + adesivo); com LTD (Control-LTD: Monobond S + adesivo; MoP-LTD: Monobond plus + adesivo; MZPLTD: Meta/Zirconia primer + adesivo). LTD foi simulada em autoclave $\left(134^{\circ} \mathrm{C}, 2\right.$ bar, 5 h). Os blocos de cerâmica foram embutidos em cilindros de PVC com resina acrílica autopolimerizável; cada tratamento de superfície foi realizado; um cilindro de resina composta (Ø: $3,25 \mathrm{~mm} 3 \mathrm{~mm}$ de altura) foi confeccionado usando matrizes metálicas bipartidas. Todos os espécimes foram envelhecidos (termociclagem + armazenagem em água por 90 dias) e sujeitos ao teste de cisalhamento usando um equipamento de teste universal $(1 \mathrm{~mm} /$ min). O modo de falha foi classificado em quatro grupos: adesivo, fratura coesiva em resina composta, fratura coesiva da cerâmica, e mista. Os valores de adesão foram sujeitos ao teste de Mann-Whitney. Resultados: somente as amostras jateadas (TBS e TBSLTD) sobreviveram a termociclagem. Mais que $80 \%$ dos espécimes dos outros grupos apresentaram falhas préteste. Os grupos TBS apresentaram os maiores valores de resistência ao cisalhamento $(3,94)$ comparado com TBS-LTD $(0,96)$. Os tipos predominantes de falha para os espécimes sobreviventes foi adesiva. Conclusão: o jateamento é recomendável para aumentar a resistência adesiva à zircônia; um substrato envelhecido apresenta um cenário mais desfavorável de adesão.

\section{PALAVRAS-CHAVE}

Reparo em prótese dental; Degradação hidrotérmica; Zircônia; Resistência de união ao cisalhamento; Jateamento. 


\section{INTRODUCTION}

Y ttria-stabilized polycrystal tetragonal zirconia (Y-TZP) consists of a polycrystalline ceramic material characterized by high flexural strength, fracture toughness, and fatigue resistance [1]. However, it exhibits high opacity, thus requiring a veneering material made of a vitreous-based ceramic for improved aesthetic results [2]. Unfortunately, the fractures or delamination/chippings of this veneer ceramic have been recognized as the major complication of this type of restoration [2]. In several cases, even the exposure of the infrastructure material may occur after chipping [3]. Hence, in such scenarios, the use of intra-oral methods of repair (based on the use of composite resins) may be a conservative alternative that can increase the lifetime of this restoration until it finally undergoes a real need of replacement [4].

Although zirconia consists of a chemically biological inert material (which is a beneficial characteristic), it presents a clinical challenge in a restorative dentistry context, which is the difficulty in achieving adequate adhesion [1]. The gold-standard surface treatment for enhanced adhesion on porcelain materials (glass-ceramics) involves etching with hydrofluoric acid (5\% to 10\%) followed by the application of a silane-bonding agent, which, when associated with resin cements, results in increased bond strength [5]. Nevertheless, this traditional adhesive technique is not effective for zirconia-based ceramics, due to its crystalline nature and non-reactive surface, which renders them resistant to the effects of etching with hydrofluoric acid [6].

Therefore, zirconia-based ceramics require alternative methods of surface modification for adhesion. Accordingly, numerous techniques have been proposed in the literature. Among them, the most commonly used technique is tribochemical treatment [7], which includes air abrasion with aluminum particles coated with silica followed by the application of a silanebased primer; or air abrasion with alumina particles [4] followed by surface activation with adhesion promoters (primers). Both alternatives are based on simultaneously obtaining a chemically reactive surface (chemical adhesion) and an increased surface roughness, which would propitiate mechanical interlocking [1].

However, some studies showed that the air abrasion of Y-TZP ceramics with particles may lead to material degradation owing to the introduction of micro-cracks in the material surface by phase transformation $(t \rightarrow m)$, which may lead to posterior catastrophic fracture under mechanical loading/stimuli [8]. Therefore, other alternatives were proposed based solely on the use of chemical agents (primers) for zirconia, focusing on the improvement of chemical adhesion. However, previous literature still shows decreased stability of bonding after storage and thermocycling, used for artificially inducing cement hydrolysis and degradation of bonding interface [9].

As mentioned above, Y-TZP ceramics is considered a biologically inert material; however, although this fact appears undeniable [10], it is also true that this material exhibits a metastable characteristic, which leads to phase transformations that can be triggered by different stimuli. Such phase transformation mechanism is the main reason for an immediate increase in the mechanical properties but also for the long-term degradation due to a process known as low-temperature degradation (LTD) leading to a superficially increased roughness, changes of the material density, and finally compromising the mechanical properties [11].

Thus, after installment, the final prosthetic restoration becomes exposed to the harsh oral environment. In a scenario where this restoration results in a chipping fracture and a clinician may attempt a repair technique using a composite resin, it is important to consider that Y-TZP ceramic is probably present in a degraded stage, with the presence of m-phase content on its surface. Thus, clinicians have to consider and choose the best protocol for bonding with such surface, although literature is scarce and data is lacking to guide such choices. Hence, the present study aimed to evaluate: (1) the influence 
of different treatments of Y-TZP ceramics hydrothermally degraded in the bond strength to composite resin; (2) the adhesion between specimens treated with primers with and without phosphate monomers - MDP (without air abrasion). The null hypotheses were: (1) The surface pretreatment will not improve the adhesion of composite resin to Y-TZP ceramic; (2) The LTD will not affect the bond strength of composite resin to Y-TZP ceramic.

\section{MATERIAL AND METHODS}

\section{Sample size calculation}

A sample calculation using a bicaudal test was performed in OpenEpi program (Version 2) to estimate the number of specimens required for the bond strength test. The estimate was based on the findings of Vanderlei, et al. [12], considering the difference between groups with means 7.9 \pm 2.6 and $13.3 \pm 4.1 \mathrm{MPa}$, because these were the groups presenting statistically significant difference and the smallest difference between the means. Applying these parameters, $80 \%$ power, and a significance level of $5 \%$, seven specimens per group were determined to be necessary. However, we decided to adopt 15 specimens per group in this study to obtain a safety margin.

\section{Sample preparation}

With the aid of a cutting machine (IsoMet ${ }^{\circledR}$ 1000 / Buehler, Lake Bluff, USA)), ceramic blocks of Y-TZP (VITA In-Ceram 2000 YZ cubes for inLab, Bad Sackingen, Germany) were cut, thus obtaining 135 specimens ( $4 \mathrm{~mm}$ height) with an adhesive surface area of approximately $5 \times 5 \mathrm{~mm}$, which were subsequently polished with Sof-Lex discs (3M/ESPE) and 1200-grit silicon carbide papers so that their surfaces were regularized and any defect introduced by cutting was removed. The specimens were sintered according to the manufacturer's recommendations (heat rate 1: $60^{\circ} \mathrm{C} / \mathrm{min}$ up to $700{ }^{\circ} \mathrm{C}$; heat rate $2: 60{ }^{\circ} \mathrm{C} /$ min up to $1300^{\circ} \mathrm{C}$; heat rate $3: 40{ }^{\circ} \mathrm{C} /$ min up to $1530^{\circ} \mathrm{C}$ : dwell time: $25 \mathrm{~min}$, followed by slow cooling by opening the furnace at temperatures below $400^{\circ} \mathrm{C}$ ), resulting in the final dimensions of approximately $4 \times 4 \mathrm{~mm}$ of bonding area $\times 3 \mathrm{~mm}$ (height) and subsequently subjected to ultrasonic cleaning with isopropyl alcohol for $10 \mathrm{~min}$.

After the preparation, 105 specimens were subjected to LTD in an autoclave (Sercon HS1-0300 n11560389/1, Mogi das Cruzes, Brazil), at $134{ }^{\circ} \mathrm{C}, 2$ bar pressure for $5 \mathrm{~h}$, which corresponded to approximately 15-20 years in vivo [13]. The monoclinic phase content should not exceed the maximum of $25 \%$ for Y-TZP implants to be considered suitable for biomedical purposes after aging under this protocol [14].

The remaining specimens (45) were not subjected to LTD. Subsequently, the specimens were divided into 9 groups (Table 1), considering the factor surface treatment (Table 2).

\section{Shear bond strength test (SBS)}

Each specimen of Y-TZP was embedded with acrylic resin of chemical polymerization (VIPI Flash, VIPI, Pirassununga, Brazil), inside of a plastic cylinder ( $\mathrm{h}=14 \mathrm{~mm}$ and $\varnothing=25$ $\mathrm{mm}$ ). The specimens were fixed with a doublesided tape onto a glass plate. Subsequently, the plastic cylinder was positioned and the acrylic resin was placed on the plastic cylinder, but leaving a surface of ceramic to the adhesion of acrylic resin.

Specimens surfaces were treated according to the description presented in Table 2. All the groups received a layer of adhesive (Adper Scothbond Multi-purpose Plus Adhesive, 3M ESPE, St Paul, USA), except the single bond universal group (SBU, 3M ESPE, St Paul, USA). Subsequently, split metallic matrices $(\varnothing=3.25$ $\mathrm{mm}$ and height $=3 \mathrm{~mm}$ ) were positioned on the treated zirconia surface, and the composite resin (Filtek Z350 XT, 3M ESPE, St Paul, USA) was inserted into the matrices (two increments: approximately $1.5 \mathrm{~mm}$ and $10 \mathrm{~s}$ of curing in the first increment and $1.5 \mathrm{~mm}$ and $40 \mathrm{~s}$ of curing in the second increment) (Radii-cal, SDI; Bayswater, VIC, Australia - power output of $1200 \mathrm{~mW} / \mathrm{cm}^{2}$ ). The circular cross-section adhesive area was $8.3 \mathrm{~mm}^{2}$. 
The shear test was performed using a universal testing machine (EMIC DL-2000 Pinhais, Brazil) at a speed of $1 \mathrm{~mm} / \mathrm{min}$, and the load was applied perpendicular to the adhesive interface until the occurrence of the failure. The test was conducted with a chisel device. The bond strength was calculated as $\mathrm{R}=\mathrm{F} / \mathrm{A}$, where $R$ is the resistance (MPa), $F$ is the charge required to break the specimen $(\mathrm{N})$, and $\mathrm{A}$ is the interfacial area of the specimen $\left(\mathrm{mm}^{2}\right)$.

\section{Thermocycling}

The groups were subjected to thermocycling (number of cycles: 10,000; temperature: $5{ }^{\circ} \mathrm{C}-55{ }^{\circ} \mathrm{C}$ with $30 \mathrm{~s}$ in each bath and $4 \mathrm{~s}$ between baths, Nova Etica, Sao Paulo, Brazil) and subsequently stored in distilled water at $37^{\circ} \mathrm{C}$ for 90 days before the specimens were shear tested.

\section{Analysis of failure mode}

All the samples were analyzed under stereomicroscopy (Discovery V20, CarlZeiss, Gottingen, Germany)) with increased magnification (10-60x) to identify the type of failure, which were classified into: 1) adhesive (ADES): fracture at the interface between adhesive/primer and ceramic; 2) composite resin cohesive fracture (COES-CR); 3) ceramic cohesive fracture (COES-cer); 4) mixed (MIST): adhesive fracture combined with composite cohesive fracture.

\section{Statistical analysis}

The nominal values of bond strength were recorded in $\mathrm{MPa}$ and tabulated in a statistic software (SPSS version 21, IBM, Chicago, Illinois, USA). Specimens that failed during the thermocycling were assigned a bond strength value of $0.01 \mathrm{MPa}$. In order to verify the normality of distribution, we used the ShapiroWilk test. The bond strength data were not parametric; therefore, the values were subjected to the Mann-Whitney test (5\%).

\section{RESULTS}

Only TBS and TBS-LTD groups presented specimens that survived to thermocycling. All specimens of the remaining groups (those not air abraded) failures during the aging. More than $50 \%$ of specimens of TBS and TBS-LTD had SBS values after thermocycling. Hence, we assigned a bond strength value of $0.01 \mathrm{MPa}$ to the other half of the specimens of these groups. The mean values and pre-test failure numbers (\%) are presented in Table 3.

\section{DISCUSSION}

The null hypothesis (1) was rejected because air-abraded groups (TBS-LTD, TBS) exhibited statistical difference in relation to the other groups. All the groups that were not previously air abraded exhibited high incidence of spontaneous debonding during thermocycling (Table 3). This can be due to the weak bonding between Y-TZP and composite resin, highlighting the importance of the surface pretreatment of zirconia. Besides, it also has to be considered that the aging protocol adopted herein (thermocycling for 10.000 cycles + storage for 90 days) may consist in an extremely harsh aging scenario, especially in comparison to protocols in the previous literature (fewer cycles or less time, rarely associated); we emphasize that we opted for this protocol exactly due to its harsh characteristics, to elucidate a potential to enhance adhesion even in such environment.

Recently, many adhesion studies of ceramics are being published with thermal aging protocols above to the one recommended by ISO 11405:2003 (thermocycling test comprising of 500 cycles in water between $5{ }^{\circ} \mathrm{C}$ and $55{ }^{\circ} \mathrm{C}$, starting after $20 \mathrm{~h}$ to $24 \mathrm{~h}$ storage in water at 37 ${ }^{\circ} \mathrm{C}$ and/or long-term test after six-month storage in water at $37^{\circ} \mathrm{C}$ ). In the current study we used 10.000 cycles and storage for 90 days. The use of such protocol could be the most probable reason for the low values obtained on shear bond strength test. It is stated that thermocycling and the water storage are aggressive environments to adhesive interfaces that degrades the bond strength [15] and the long artificial aging is important to water saturation in composites, leading to hydrolytic degradation of the adhesive interface [16]. According to Sarret, et al. [17] 
most of water absorption of composites occurs at the first two months of storage. So, although such aging protocol did not mimic clinical environment it consists on a valid tool to assess adhesion stability, in this sense the performance observed was very concerning and more studies should be made to attempt on optimization of such outcome.

The air abrasion with alumina particles coated with silica under pressure modifies the zirconia surface, thus promoting an increase of roughness [4] and chemical compatibility with adhesive primers [1]. Thus, possibly, the absence of mechanical interlocking on non-air-abraded groups favored water penetration (hydrolysis of adhesive interface) causing debonding failures [18].

In the current study, traditional/ conventional (silane-Monobond S), MDP (ester phosphate groups-Monobond Plus, Alloy Primer and Single Bond Universal), and phosphonic acid acrylate (MZP) primers were used without air abrasion of the surface as pretreatment. In such groups the adhesive interaction forces are formed between functional monomers and metal ions [19]. As zirconia ceramics consist of metal oxides, adhesive monomers may interact with these oxides forming chemical bonds, such as van de Waals forces or hydrogen bonds on the adhesive interface (resin-zirconia) and improve the surface wettability of zirconia [20].

The groups that were not air-abraded (AP-LTD, Control-LTD, USB, Control, MoPLTD, MoS-LTD, and MZP-LTD), no matter the monomer type, exhibited high percentage of pre-test failures during thermocycling (Table 3 ) indicating that the absence of mechanical interlocking promoted by air abrasion negatively affected the adhesion between the composite resin and aged Y-TZP. These results are in accordance with Pereira, et al. [21]. Yang, et al. [25] showed that the initial bond strength of zirconia specimens without air abrasion and chemically treated with phosphate primers was improved; however, after long-term storage, the chemical bonds were not water resistant. Hence, the mechanical pretreatment may be essential to achieve adequate adhesion in association with a chemical step (primer) [4,26,27].

Some studies described interesting adhesion results between MDP-based primers (10-methacryloxydecyl dihydrogen phosphate monomer) and Y-TZP ceramics owing to the supposed adhesive interaction of the ester phosphate groups with the zirconia metal oxides [28]; however, this phenomenon was not observed in the current study. Amaral, et al. [27] achieved higher percentage of specimens cemented with MDP primers that survived thermocycling; however, the bonding values were lower compared to those of the air-abraded specimens, partially in accordance with our results. Spontaneous failures during aging were also observed by Kern, Barloi and Yang [20] and Cristoforides, et al. [4].

A conventional MPS-based primer (methacryloxypropyltrimethoxy-silane, Monobond S) was also used in the current study and exhibited high losses during thermocycling. It has been demonstrated that the use of conventional silane results in an increase in the bonding strength between Y-TZP surfaces air-abraded with alumina particles coated with silica; however, this mechanism is not sustained on surfaces without silica deposition [1,24].

Regarding the use of phosphonic acid acrylate-based primer (Metal/Zirconia Primer), according to the manufacturer, this product promotes adhesion between ceramics oxides and methacrylate composites. In the current study, this primer did not promote a stable adhesion, resulting in debonding during aging, which was also observed by Cristoforides, et al. [4].

Another important aspect is that the low-temperature degradation (LTD) affected the bond strength negatively, as observed by comparing TBS and TBS-LTD (Table 3), and hence, the null hypothesis (2) was rejected. It is stated that, after some stimuli (such as aging), a phase transformation $(t \rightarrow m)$ on superficial grains may occur [11], leading to a volume increase (3 to 4\%) around these grains and the introduction of superficial residual stress 
(compression) on the surface of zirconia [23]. This mechanism can have either a positive or negative effect on the properties of Y-TZP, depending on the intensity of the stimuli and $m$-phase content post-transformation [29].

The increase of residual stresses in response to the volume expansion promoted by phase transformation may inhibit the crack propagation and improve the flexural strength of Y-TZP [23]; however, as the monoclinic phase transformation mechanism proceeds towards the bulk of the Y-TZP ceramic [30], the internal flaws and effects of degradation can be critical. It is known that LTD produces phase transformation within a layer of 6 to 20 $\mu \mathrm{m}$ on the surface of zirconia, changing the roughness and texture of the surface ${ }^{3}$ owing to grain pull-out [22]. Moreover, the air abrasion promotes a topographic alteration within a layer of approximately $15 \mu \mathrm{m}$ [31] on the surface of zirconia.

Thus, it is possible that the compressive layer introduced by phase transformation on the surface (compressive stress layer) makes the penetration of silica-coated alumina particles difficult (TBS-LTD group); or that the air-abrasion of transformed grains had resulted in a silica deposition on grains that were not firmly adhered to the core material, potentially being easily detached and leading to decreased adhesion. This needs further investigation. In contrast to these results, Galvão Ribeiro, et al. [24] evaluated the effect of airborne-particle abrasion (sandblasting with $\mathrm{Al}_{2} \mathrm{O}_{3}$ or silica-coated $\mathrm{Al} 2 \mathrm{O} 3$ particles) and a bonding agent on the shear bond strength at the zirconia ceramic-composite resin interface to find that hydrothermal aging did not influence the bonding.

Despite the present inhomogeneous stress distribution, the shear bond test is the most commonly used method and an acceptable alternative to bonding tests, principally compared to the microtensile bond strength test of zirconia specimens because cutting procedures can cause damage to the adhesive interface [4]. In relation to the mode of failure (Table 4), the majority of specimens exhibited adhesive failures for both after shear bond strength test (Figures 1AB: fracture at the interface between adhesive/primer and ceramic) as during thermocycling (Figure 1C).

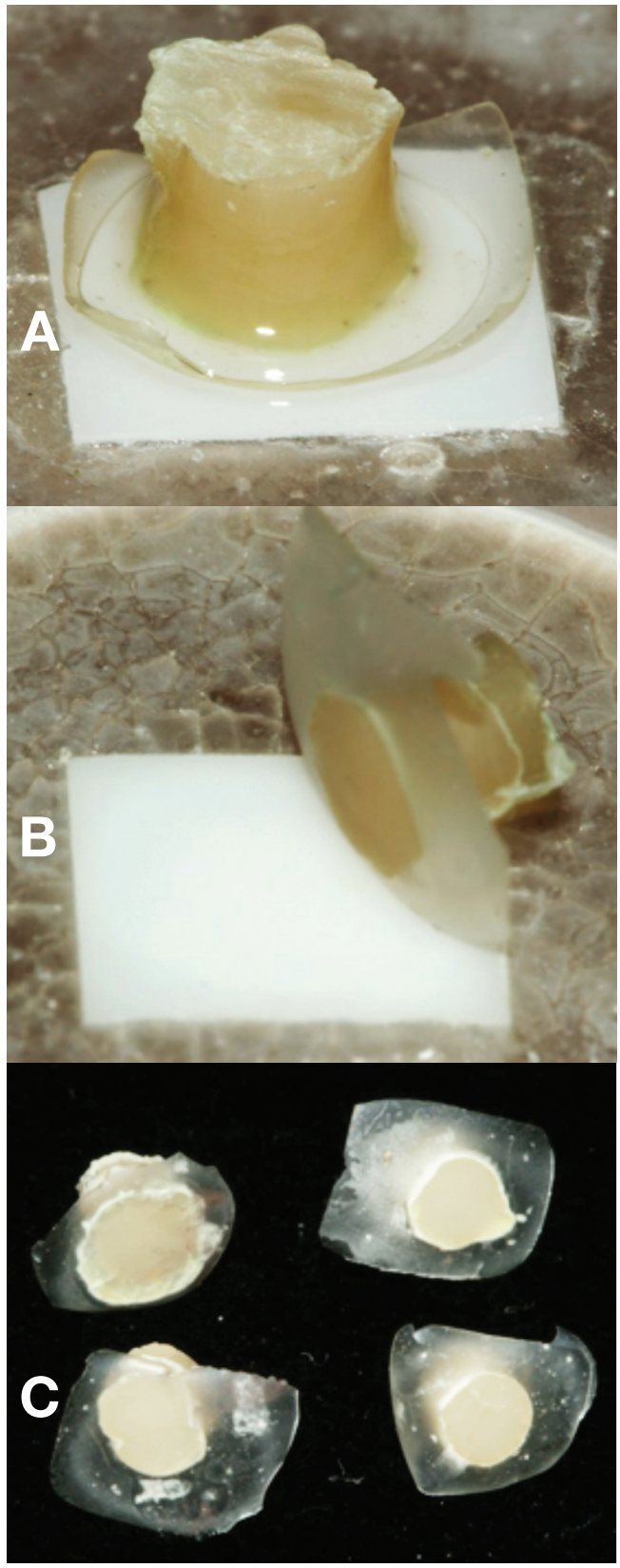

Figure 1 - Representative images of the failure analysis. A. Alloy Primer specimens group. It is possible to observe the adhesive layer detached of the zirconia surface. B. Single Bond Universal specimen group. Adhesive layer adhered on composite resin cylinder. C. Adhesives spontaneous failures occurred during the aging. Note the adhesive layer attached on the composite cylinder.

Clinically, a zirconia crown with veneer chipping would present an occlusal surface with a porcelain/vitreous ceramic exposed. As vitreous ceramics are etchable by hydrofluoric acid, the repair procedure would involve different conditionings on the exposed zirconia 
and vitreous ceramics surfaces. Hence, it is possible for the clinical adhesion to be more efficient owing to the etchable ceramic. Further, in a clinical situation, the Y-TZP framework would exhibit some degree of roughness caused

Table 1- Experimental design of the study. by machining, which promotes the mechanical interlocking with the repair composite. Further studies to simulate the real condition of a veneered zirconia crown, which is chipped and repaired, subjected to mechanical fatigue and survival analysis are required.

\begin{tabular}{|c|c|c|}
\hline Group $(n=15)$ & Surface Treatment & LTD \\
\hline Control-* & without treatment + adhesive (Scotchbond, 3M ESPE) & Yes \\
\hline TBS - LTD & Cojet TBS cojet + silane (Ceramic primer, 3M ESPE) + adhesive (Scotchbond, 3M ESPE) & Yes \\
\hline MoS & Monobond S (Ivoclar Vivadent) + adhesive (Scotchbond, 3M ESPE) & Yes \\
\hline MoP & Monobond Plus (Ivoclar, Vivadent) + adhesive (Scotchbond, 3M ESPE) & Yes \\
\hline MZP & Metal/Zirconia Primer (Ivoclar, Vivadent) + adhesive (Scotchbond, 3M ESPE) & Yes \\
\hline TBS $^{*}$ & Cojet TBS cojet (3M ESPE) + silano (Ceramic primer, 3M ESPE) U adhesive (Scotchbond, 3M ESPE) & No \\
\hline SBU & SB universal (3MESPE) & Yes \\
\hline AP & Alloy primer (Kuraray) + adhesive (Scotchbond, 3M ESPE) & Yes \\
\hline Control +* & Without treatment + adhesive (Scotchbond, 3M ESPE) & Yes \\
\hline
\end{tabular}

* Evaluation of the adhesive effect in the adhesion to zirconia.

Abbreviations: Control-: negative control group; TBS - LTD: tribochemical silica coating with low temperature degradation group; MoS: Monobond S; MoP: Monobond Plus; MZP: Metal/Zirconia Primer; TBS: tribochemical silica coating; SBU: Single bond universal; AP: Alloy Primer; Control +: positive control group.

Table 2 - Surface treatments used in the study as well their compositions, brands and use mode.

\begin{tabular}{|c|c|c|c|}
\hline Treatment & Composition & Manufacturer & Use $^{*}$ \\
\hline $\begin{array}{l}\text { Tribochemical } \\
\text { silica coating }\end{array}$ & $\mathrm{Al}_{2} \mathrm{O}_{3}$ particles coated with silica $(30 \mu \mathrm{m})$ & $\begin{array}{c}\text { Cojet Sand - 3M } \\
\text { ESPE }\end{array}$ & $\begin{array}{c}2.8 \text { bar pressure, } 7 \mathrm{~s}, 10 \text { mm distance + RelyX Ceramic } \\
\text { Primer. }\end{array}$ \\
\hline Monobond S & Alcohol solution of silane methacrylate. & Ivoclar Vivadent & $\begin{array}{l}\text { Applied on zirconia surface with a microbrush, wait for } 60 \\
\text { seconds and dispersed with a strong stream of air }\end{array}$ \\
\hline $\begin{array}{l}\text { RelyX Ceramic } \\
\text { Primer }\end{array}$ & 3-MPS, ethyl alcohol, water & 3MESPE & $\begin{array}{c}\text { Applied with a microbrush, wait for } 5 \text { seconds before } \\
\text { drying with an oil-free air stream }\end{array}$ \\
\hline Monobond Plus & $\begin{array}{l}\text { Ethanol,3-trimethoxysilylpropyl methacrylate, 10-MDP, } \\
\text { sulphide methacrylate }\end{array}$ & Ivoclar Vivadent & $\begin{array}{l}\text { Applied on zirconia surface with a microbrush, wait for } 60 \\
\text { seconds and dispersed with a strong stream of air }\end{array}$ \\
\hline $\begin{array}{l}\text { Single Bond } \\
\text { Universal }\end{array}$ & $\begin{array}{l}\text { 10-MDP monomer, dimethacrylate resins, HEMA, } \\
\text { methacrylate-modified polyalkenoic acid copolymer, } \\
\text { filler, ethanol, water, initiators, silane }\end{array}$ & 3MESPE & $\begin{array}{l}\text { Applied with a microbrush for } 20 \mathrm{~s} \text {, dried with a gentle air } \\
\text { stream for } 5 \mathrm{~s} \text { to evaporate solvent, and light cured for } 10 \mathrm{~s} \text {. }\end{array}$ \\
\hline $\begin{array}{l}\text { Metal/Zirconia } \\
\text { Primer }\end{array}$ & $\begin{array}{l}\text { Phosphonic acid acrylate, dibenzoyl peroxide, methyli- } \\
\text { sobutylketone, tert-butyl alcohol }\end{array}$ & Ivoclar Vivadent & $\begin{array}{l}\text { Applied with a microbrush, wait for } 180 \mathrm{~s} \text { and dispersed } \\
\text { with a strong stream of air for } 5 \mathrm{~s} \text {. }\end{array}$ \\
\hline Alloy Primer & 10-MDP, VBATDT, acetone & Kuraray & $\begin{array}{l}\text { Applied with a microbrush, wait for } 10 \mathrm{~s} \text { and gently air dry } \\
\text { for } 5 \mathrm{~s} \text {. }\end{array}$ \\
\hline $\begin{array}{l}\text { Adper Scothbond } \\
\text { Multi-purpose } \\
\text { Plus Adhesive }\end{array}$ & Bis-GMA, HEMA, tertiary amines, photoinitiator & 3MESPE & Applied with a microbrush and ligh cure for $10 \mathrm{~s}$. \\
\hline Filtek Z350 XT & $\begin{array}{l}\text { Bis-GMA, TEG-DMA, UDMA, PEG-DMA, bis-EMA, } \\
\text { Zirconium/Silicium cluster }\end{array}$ & 3MESPE & $\begin{array}{l}\text { An increment of } 1.5 \mathrm{~mm} \text { and } 10 \mathrm{~s} \text { of curing and other of } 1.5 \\
\mathrm{~mm} \text { and } 40 \mathrm{~s} \text { of curing. }\end{array}$ \\
\hline
\end{tabular}

${ }^{*}$ After the surface treatment, all groups received the adhesive application (Adhesive component of the Adper Scotchbond Multi-purpose Plus except Single Bond Universal group).

Abbreviations: 10-MDP: 10-methacryloyloxdecyl dihydrogen phosphate; HEMA: 2-hydroxyethyl methacrylate; VBATDT: 6-(4- vinylbenzyl-npropyl) amino-1,3,5-triazine-2,4-dithione; 3-MPS: 3-methacryloyloxypropyl trimethoxysilane; Bis-GMA: bisphenol A diglycidyl methacrylate; TEG-DMA: triethyleneglycol dimethacrylate; bis-HEMA: ethoxylated bisphenol-A dimethacrylate; UDMA: urethane dimethacrylates; PEGDMA: poly(ethylene glycol) dimethacrylate. 
Table 3 - Shear bond strength values means $(\mathrm{MPa}) \pm$ standard deviation $(\mathrm{SD})$ and pre-test failures.

\begin{tabular}{|ccc|}
\hline Groups & Means \pm SD & Pre-test failures during thermocycling - No. (\%) \\
\hline TBS & $3.94 \pm 2.64$ A & $1(7)$ \\
\hline TBS - LTD & $0.96 \pm 1.84 \mathrm{~B}$ & $8(50)$ \\
\hline AP & - & $13(87)$ \\
\hline Control - & - & $15(100)$ \\
\hline USB & - & $13(87)$ \\
\hline Control & - & $15(100)$ \\
\hline MoP & - & $12(80)$ \\
\hline MoS & - & $13(87)$ \\
\hline MZP & - & $14(93)$ \\
\hline
\end{tabular}

The groups that presented more than $50 \%$ of pre-test failures were not included in the statistical analysis.

Table 4 - Failure mode classification during the thermocycling and after shear bond strength

\begin{tabular}{|cccccc}
\hline Groups & LTD & \multicolumn{3}{c}{ Failure Mode (\%) } \\
\hline Control - & Yes & $15(100)$ & COES-CR $^{*}$ & COES-CER & M $^{*}$ \\
\hline TBS & Yes & $15(100)$ & - & - & - \\
\hline MoS & Yes & $15(100)$ & - & - & - \\
\hline MoP & Yes & $15(100)$ & - & - & - \\
\hline MZP & Yes & $15(100)$ & - & - & - \\
\hline TBS - LTD & No & $15(100)$ & - & - & - \\
\hline ZP & Yes & $15(100)$ & - & - & - \\
\hline AP & Yes & $14(93)$ & - & - & - \\
\hline Control + & No & $14(93)$ & $1(7)$ & $1(7)$ & - \\
\hline
\end{tabular}

${ }^{*}$ ADES: fracture at the interface between adhesive/primer and ceramic.

COES-CR: Composite resin cohesive fracture.

COES-CER: Ceramics cohesive fracture.

M: adhesive fracture combined with composite resin cohesive fracture.

\section{CONCLUSION}

- The air abrasion were fundamental for the adhesion between composite resin and aged and non-aged Y-TZP.

- It suggests that an aged Y-TZP substrate is an even more challengeable scenario for achieving adhesion to resinous materials, given the low bond strengths.

\section{REFERENCES}

1. Thompson JY,Stoner BR, Piascik JR, Smith R. Adhesion/cementation to zirconia and other non-silicate ceramics: Where are we now? Dent Mater.2011 Jan:27(1):71-82

2. Raigrodski AJ, Hillstead MB, Meng GK, Chung KH. Survival and complications of zirconia-based fized dental prostheses: a systematic review. J Prosthet Dent 2012Mar;107(3):170-7.

3. Sailer I,Makarov NA, Thoma DS, Zwahlen M, Pjetursson BE. All-ceramic or metal-ceramic tooth-supported fixed dental prostheses (FDPs)? A systematic review of the survival and complication rates. Partl: Single crowns (SCs). Dent Mater.2015Jun;31(6):603-23. 
4. Cristoforides P,Amaral R, May LG, Bottino MA, Valandro LF.Composite resin to yttria stabilized tetragonal zirconia polycrystal bonding: comparison of repair methods. Oper Dent 2012May-Jun;37(3):263-71.

5. Chen JH, Matsumura H, Atsuta M. Effect of different etching periods on the bond strength of a composite resin to a machinable porcelain. J Dent 1998 Jan;26(1):53-8.

6. Kitayama S, Nikaido T,Maruoka R, Zhu L, kkeda M, Watanabe A. Effect of an internal coating technique on tensile bond strengths of resin cements to zirconia ceramics. Dent Mater J. 2009;28(6):446-53.

7. Attia A. Bond strength of three luting agents to zirconia ceramic-Influence of surface treatment and thermocycling. J Appl Oral Sci. 2011 Aug;19(4):388-95.

8. Zhang Y,Lawn B, Rekow ED, Thompson VP. Effect of sandblasting on the longterm performance of dental ceramics. J Biomed Mater Res B Appl Biomater. 2004 Nov 15;71(2):381-6

9. Matinlinna JP, Lassila LV, Vallittu PK. Pilot evaluation of resin composite cement adhesion to zirconia using a novel silane system. Acta Odontol Scand. 2007 Feb;65(1):44-51.

10. Kanchana S, Hussain SDr.Zirconia a Bio-inert Implant Material. J Dent Med Sci. 2013 Nov-Dec;12(6):66-7.

11. Chevalier J, Gremillard L, Deville S. Low-temperature degradation of zirconia and implications for biomedical implants. Annu Rev Mater Re. 2007 Apr;37:1-32.

12. Vanderlei $A, B o t t i n o ~ M A$, Valandro LF Evaluation of resin bond strength to yttria-stabilized tetragonal zirconia and framework marginal fit: comparison of different surface conditionings. Oper Dent. 2014 Jan-Feb;39(1):50-63.

13. Chevalier J, Cales B, Drouin JM. Low-temperature aging of Y-TZP ceramics. J Am Ceram Soc. 1999 Aug;82(8):2150-4.

14. Siarampi E, KontonasakiE, Andrikopoulos KS, Kantiranis N, Voyiatzis GA, Zorba $T$, et al. Effect of in vitro aging on the flexural strength and probability to fracture of Y-TZP zirconia ceramics for all- ceramic restorations. Dent Mater.2014 Dec;30(12):e306-16.

15. De Munck J, Van LanduytK, Peumans M, Poitevin, Lambrechts P,Braem M, et al. A critical review of the durability of adhesion to tooth tissue: methods and results. J Dent Res. 2005 Feb;84(2):118-32.

16. Kern $\mathrm{M}$, Thompson VP. Bonding to glass infiltrated alumina ceramic: adhesive methods and their durability. JProsthetDent. 1995 Mar;73(3):240-9.

17. SarrettDC, Söderholm KJ, Batich CD. Water and abrasive effects on threebody wear of composites. J Dent Res. 1991Jul;70(7):1074-81.

18. Blatz MB, Richter C, Sadan A, Chiche GJ. Resin bond to dental ceramics, partii: high-strength ceramics. J Esthet Restor Dent. 2004;16(5):324-8.
19. Atsu SS, Kilicarslan MA, Kucukesmen HC, AkaPS. Effect of zirconiumoxide ceramic surface treatments on the bond strength to adhesive resin.J Prosthet Dent. 2006 Jun;95(6):430-6.

20. Kern M, Barloi A, Yang B. Surface conditioning influences zirconia ceramic bonding.JDentRes. 2009 Sep;88(9):817-22.

21. Pereira Lde L,Campos F,Dal Piva AM, Gondim LD, Souza RO, Özcan M. Can application of universal primers alone be a substitute for airborne-particle abrasion to improve adhesion of resin cement to zirconia? J Adhes Dent. 2015 Apr;17(2):169-74.

22. Flinn BD, Raigrodski AJ, Singh A, MancI LA. Effect of hydrothermal degradation on three types of zirconias for dental application. JProsthet Dent. 2014 Dec;112(6):1377-84. doi: 10.1016/.jprosdent.2014.07.015.

23. Piconi C,Maccauro G. Zirconia as a ceramic biomaterial. Biomaterials. 1999 Dec;20(1):1-25.

24. Galvão Ribeiro BR, Galvão Rabelo Caldas MR, Almeida AA Jr,Fonseca RG, Adabo GL. Effect of surface treatments on repair with composite resin of a partially monoclinic phase transformed yttrium-stabilized tetragonal zirconia JProsthetDent.2018 Feb;119(2):286-91.

25. Yang B, WolfartS, Scharnberg M, Ludwig K, Adelung R, Kern M. Influence of contamination on zirconia ceramic bonding. J Dent Res. 2007 Aug;86(8):74953.

26. Inokoshi M, Kameyama A, De Munck J, Minakuchi S, Van Meerbeek B. Durable bonding to mechanically and/or chemically pre-treated dental zirconia. JDent. 2013 Feb;41(2):170-9.

27. Amaral M,Belli R, Cesar PF,Valandro LF, Petschelt A, Lohbauer U. The potential of novel primers and universal adhesives to bond to zirconia. J Dent. 2014 Jan;:42(1):90-8.

28. Blatz MB, Phark J-H, Ozer F,ManteFK, Saleh N, Bergler M, etal. In vitro comparative bond strength of contemporary self-adhesive resin cements to zirconium oxide ceramic with and without air-particle abrasion. Clin Oral Investig. 2010;14(2):187-92.

29. Kim HT, Han JS, Yang JH, Lee JB, Kim SH. The effect of low temperature aging on the mechanical property \& phase stability of YTZP ceramics. J Adv Prosthodont.2009 Nov;1(3):113-7.

30. Yoshimura M. Phase stability of zirconia. Am Ceram SotBull. 1988;67(12):1950-5.

31. 3MESPE.Cojet System: Product Dossier Clinical Research 3/98.1998.29p. Available in:http:/multimedia.3m.com/mws/media/2192190/cojet-productdossier-in-english.pdf?\&fnOcojet_tp_en.pdf

\section{Vinícius Felipe Wandscher}

(Corresponding address)

R. Silva Jardim, 1175, 97010-491, Rio Grande do Sul State, Santa Maria, Brazil.

Date submitted: 2018 May 12

E-mail: viniwan@hotmail.com 